\title{
AESTHETICIZATION AND THE "SEDUCED MANAGER": BREAKING THE SILENCE OF AESTHETICIZATION OF MANAGERIAL LIFE IN SRI LANIKA'S CORPORATE SECTOR
}

\section{by}

Risini Wasana Ilangasinha

\author{
A thesis submitted to the \\ University of Sri Jayewardenepura \\ in partial fulfillment of the requirements for the \\ Degree of Master of Science in Management \\ on $22^{\text {nd }}$ March 2015
}


The work described in this thesis was carried out by me under the supervision of Dr. S.D.W. Jayawardena and a report on this has not been submitted in whole or in part to any university or any other institution for another Degree/

\section{Diploma.}

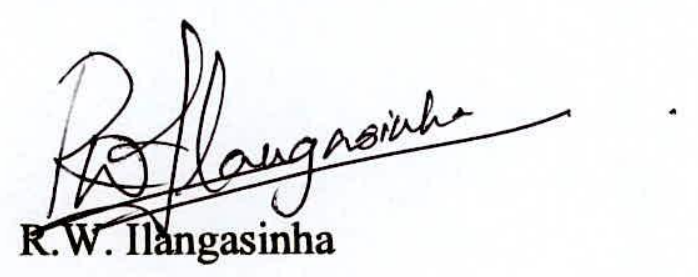


I certify that the above statement made by the candidate is true and that this thesis is suitable for submission to the University for the purpose of

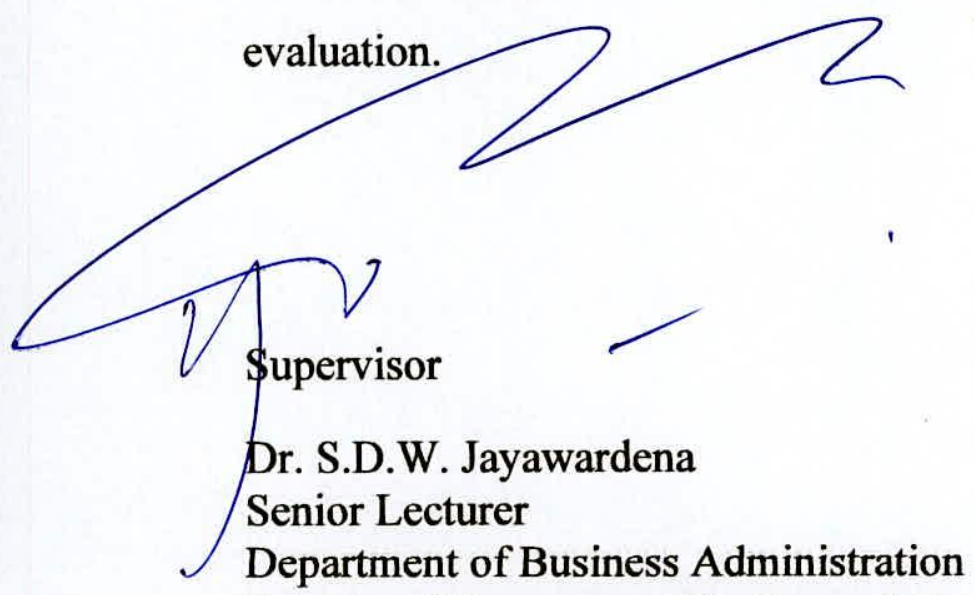

Faculty of Management Studies and Commerce

University of Sri Jayewardenepura 


\section{Table of Contents}

Acknowledgement..................................................................vi

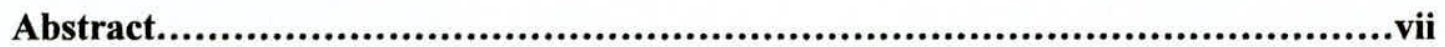

CHAPTER ONE - INTRODUCTION ............................................................................ 1

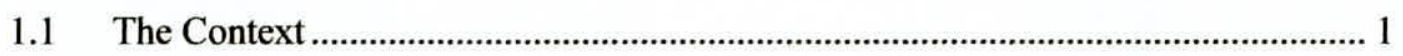

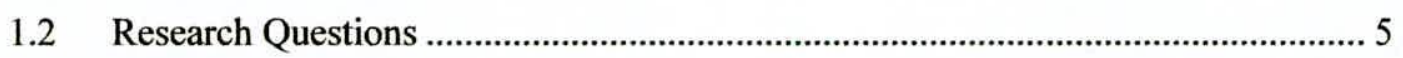

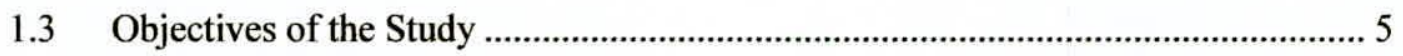

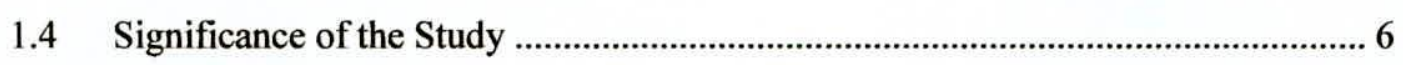

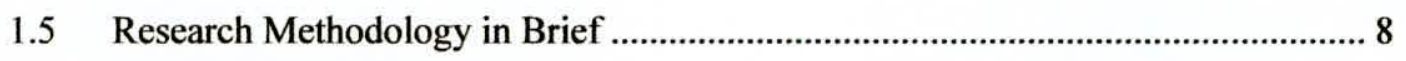

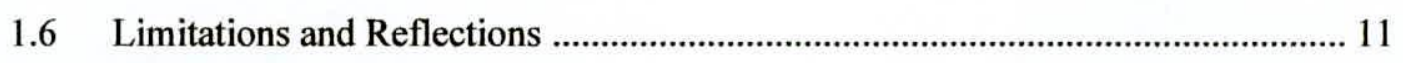

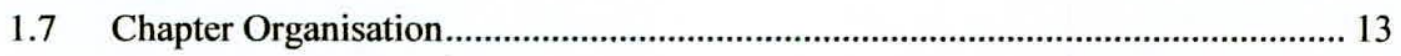

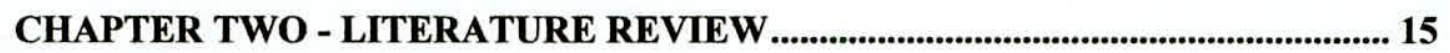

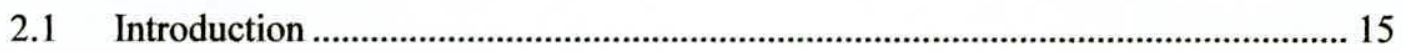

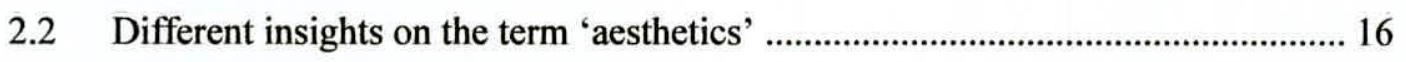

2.3 Different understandings on the concept of seduction ....................................... 22

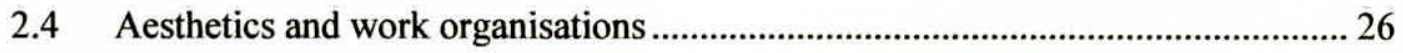


2.4.2 Exploring the aesthetic dimension of work organisations .................................... 36

2.5 The Manager and the aestheticized work organisation ......................................... 42

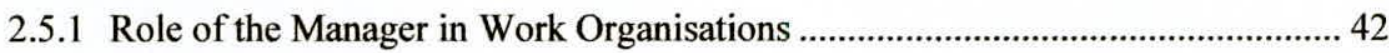

2.5.2 Organisational Aesthetics and Managerial Life ................................................. 46

2.5.3 The Aestheticized Work Organisation and the Seduced Manager ........................ 48

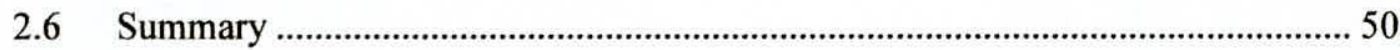

CHAPTER THREE - METHODOLOGY ......................................................................52

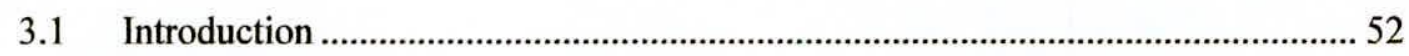

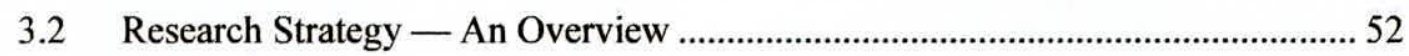

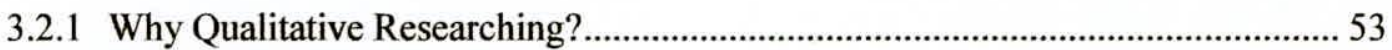

3.2.2 Rationale for Using the Photo-elicitation Technique under Visual Research

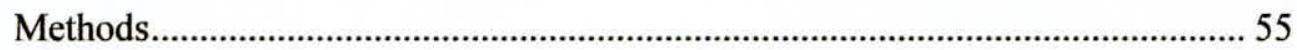

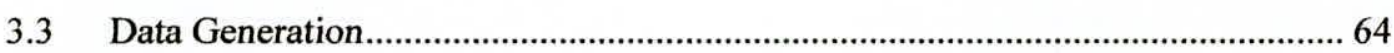

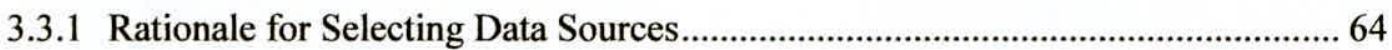

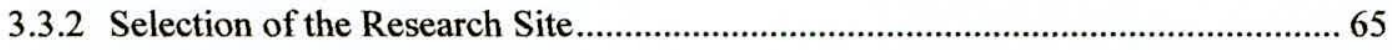

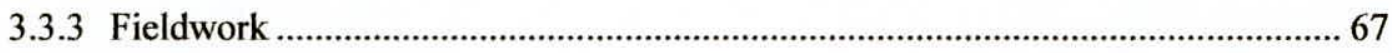

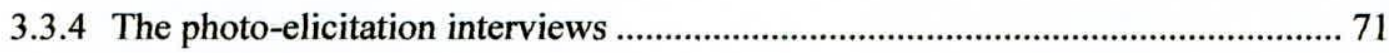




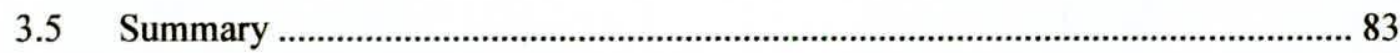

CHAPTER FOUR - DATA ANALYSIS AND DISCUSSION....................................... 85

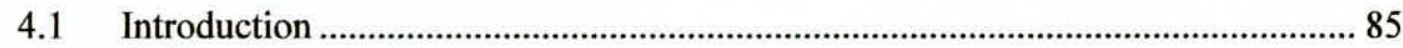

4.2 Aestheticized "world of work" at the Head Office of Apple Power ...................... 86

4.2.1 Managers' sensory perceptions on the aestheticized work environment at the Head Office. .95

4.3 Aestheticized Environment at the Factory of Apple Power 112

4.3.1 Managers' sensory perceptions on the aestheticized work environment of the Factory 116

4.3.1.1 Aestheticization as a Means of Regaining Lost Work Ardour 117

4.3.1.2 Aestheticization Being a Form of Seduction 123

4.4 Summary

5.1 Introduction

5.2 Recapitulation

5.3 Findings 134 
5.3.2 Aestheticized Managerial Life at Apple Power

5.3.3 Nature of the Two Research Settings

5.3.4 Sensing Aesthetics as a Manager - At the Head Office of Apple Power

5.3.5 Sensing Aesthetics as a Manager - At the Factory of Apple Power

5.4 Conclusions

5.5 Implications for Further Research Work

REFERENCES

\section{Table of Figures}

Figure 4.1: Buddha's Statue at the Entrance 86

Figure 4.2 : Trading Floor 87

Figure 4.3 : Lobby Area 88

Figure 4.4 : Cabins of Managers at the Trading Floor 89

Figure 4.5 : Pictures Hanging on the Wall with Motivational Quotes................................. 90

Figure 4.6: Plugbase with Colourful Pictures ..................................................................... 91

Figure 4.7: Practising Karate at the Judo base …........................................................... 92

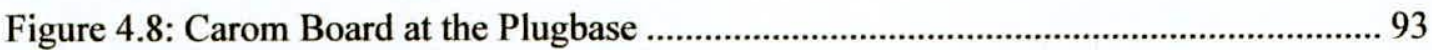

Figure 4.9: Research and Development Division at Apple Power ................................... 94 
Figure 4.10: Motivational Quotes

Figure 4.11: Research and Development Division at Apple Power ................................ 100

Figure 4.12: Boat Kept at the Entrance of Research and Development Division............... 102

Figure 4.13: Plugbase for Recreational Activities .......................................................... 105

Figure 4.14: Non Managerial Employees Playing Carom during Lunch Break................. 108

Figure 4.15: Entrance to the Factory of Apple Power ....................................................... 112

Figure 4.16: Water Fall near the Factory Premises.......................................................... 113

Figure 4.17: Ground Area with the Thatched Hut .......................................................... 114

Figure 4.18: Production Floor with Assembly Lines ...................................................... 115

Figure 4.19: Board Room in the Factory Building ....................................................... 116

Figure 4.20: Ground Area in the Factory Premises ...................................................... 117

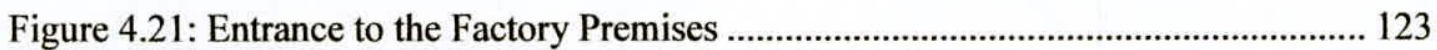

Figure 4.22: View of the Thatched Hut in an Evening .................................................... 125

Figure 4.23: Water Fall Falling Down Close to the Factory Building .............................. 126

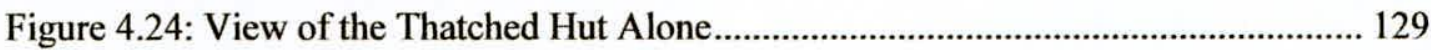

\section{List of Tables}

Table 3.1: Basic information of the research participants ................................................ 72

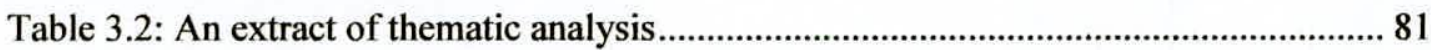




\section{Acknowledgement}

This research thesis would not have been successfully completed without the support provided by many parties. First and foremost I am grateful to my research supervisor, Dr. Dhammika Jayawardena for his valuable advice, enormous guidance and encouragement given to me. Continuous supervision of my supervisor throughout my study and the direction provided by him was instrumental in making this project a success.

Secondly, I thank the research participants and all other people who supported me in the field, without them I would have not been able to make a comprehensive study on the subject matter.

Thirdly, I would also like to take this opportunity to thank my dear colleagues Ms. Yasanthi Alahakoon, Ms. Gayani Samarakoon, Ms. Nayomi De Peiris and Ms. Vasana Kaushalya who encouraged me and supported me throughout the project for the successful conclusion of this thesis.

Finally I'm profoundly grateful to my family, specially my mother-in-law, father-in-law, my parents, Kanchana and little Thamindu for their support, understanding and patients in bringing this journey to an end. 


\title{
Aestheticization and the "Seduced Manager": \\ Breaking the Silence of Aestheticization of Managerial Life in Sri Lanka's Corporate Sector
}

\section{Risini Wasana Ilangasinha}

\begin{abstract}
Aestheticization of work organisations is a phenomenon which occurs in the contemporary world and apparently this has an influence on the lives of organisational members in diverse manners. In this context, this research study mainly explores how the managerial life is being aestheticized and the ways in which it affects the lives of managers in contemporary work organisations in Sri Lanka. Further it explores whether aestheticization leads to seduce managerial workers and if so, explores the consequences of 'being seduced' in the lives of managerial workers in Sri Lanka. In this exploration, the feelings, emotions, experiences and aesthetic judgments of managerial workers in relation to the aestheticized organisational life are brought in to discussion. A qualitative research approach is adopted for the research study. Mainly data are generated and analysed through adopting the visual research method; photo-elicitation technique. A Sri Lankan corporate sector work organisation is used as the research setting for the purpose of data generation. Based on the findings the study mainly concludes that, the way managers perceive aestheticized work environment differs with the work experience managers gain within the organisation. The aestheticization leads to seduce managerial workers and has an impact on the existence of them within the organisation, when they have to engage in stressful and repulsive nature of work, such as being in an industrialised work environment. However, aesthetics seems to
\end{abstract}


be less influential in an office environment. Managerial behaviour in such an environment is influenced by unconsciously and collectively shared managerial assumptions on the 'acceptable behaviour' a manager should demonstrate within an organisation. Thus, managers believe gaining aesthetic experiences or enjoying life at the workplace as an undesirable behaviour for a manager. At the same time, the seductive capacity of the aesthetically designed work environment is used by the managers as a tool to control the behaviour of the subordinates. Thus, the subordinates' efforts would be directed towards achieving the objectives of the organisation. Further, based on the findings it can be concluded that, aestheticized work organisation influences the identification of organisational members and leads to create a sense of pride and superiority within the minds of employees. With these findings it can be concluded that aestheticization of managerial life has an influence on the lives of managerial workers in contemporary work organisations, though the work experience that managers gain in the everyday work life matters the way in which it influences. 


\section{CHAPTER ONE INTRODUCTION}

\subsection{The Context}

In contemporary society, human beings experience aesthetics in every sphere of life. The decisions, value judgments, preferences, tastes and choices of people are influenced by different aesthetic considerations. Today, people consume on the basis of aesthetic values. Organisations are also increasingly becoming sensitive to aesthetic values. The phenomenon of aesthetics gained attention in the $19^{\text {th }}$ and $20^{\text {th }}$ centuries. The term originated from the Greek notion aisthetikos (Wesserman et al., 1998) and it is used to express things with pleasing appearances and beauty. The origin of the conceptualization of the term can be traced back to the work of the German Philosopher, Alexander Gottlieb Baumgarten (1750-1758, Aesthetica). It was introduced as a special branch of philosophy by Baumgarten (Harries, 2009; Wesserman et al., 1998). Aesthetics is perceived by the sensory cognition rather than the rational cognition of human beings. Thus, it goes in contrast to logic which has the ultimate goal of exploring the truth. Even though the term has been defined in much earlier periods by philosophers, such as Kant (1781), Vico (1725) and Hegel (1770-1831) in different perspectives, it is popularly understood as a "form of knowledge" (Harding, 2003; Strati, 2000; Gagliardi, 2006; 1999) detained directly through the five senses of human beings by experiencing the world (Taylor and Hansen, 2005).

The phenomenon - aesthetics - has gained popularity in recent times due to the high attention given to the "aesthetic sphere of existence" in the theorisation of organisations. In 
earlier periods, organisational theorising paid more attention to "instrumental" problems (regarding efficiency and effectiveness) and "moral" problems (concerned on business ethics) (Taylor and Hansen, 2005). However, with the emergence of aesthetics as an interesting area of study different scholars have conceptualized aesthetics in different perspectives. Among these scholars, Antonio Strati and Pasqual Gagliardi have contributed massively to the field of organisational aesthetics (see for example Strati, 2010, 2005, 2004, 2000, 1999, 1996; Gagliardi, 2006, 1999). Both these scholars understand aesthetics as a form of sensory knowledge which is acquired through the five senses of human beings (Gagliardi ,2006, 1999; Strati, 2000). One of the main arguments which go on - when conceptualizing aesthetics is that, it is not a phenomenon which always associates itself with beauty or attractiveness. All sorts of other experiences such as feeling disgust, ugliness and kitsch are understood as categories of aesthetics (Strati, 1996). Therefore, aesthetics refers to all forms of sensory experiences. By referring the term to 'beauty' and 'art' is the way how it is being socially described (Gagliardi, 1999).

Due to the high recognition given to aesthetics in the recent few decades, it could be observed that contemporary work organisations have an increasing interest towards incorporating aesthetic values to the working life. Today by being at work, people look for experiences rather than material benefits. As explained by Bauman (2005), "Like life's other activities, work now comes first and foremost under aesthetic scrutiny. Its value is judged by its capacity to generate pleasurable experiences"(p. 34). Therefore, organisations are currently paying great attention to designing the work environment in an attractive manner to make organisational members exposed to gain aesthetic experiences. These rapid 
aestheticization processes that are going on affect the lives of organisational members workers or managers - in various ways and it influence their existence within the organisation.

Thus, the rationale behind work place aestheticization has been brought into consideration by many scholars in the field of organisational aesthetics. As it is identified, in the present context, aesthetic attributes are incorporated into the working life in order to increase the commitment and morale of the organisational members to work towards achieving the goals and objectives of the organisation. When people are allowed to gain sensually appealing experiences they tend to work more productively, thereby aestheticization leads to enhance the performance of the organisation (Gagliardi, 1999; Schmitt \&Simonson, 1997; Weggeman, et al. ,2007). Aestheticized artefacts and activities within an organisation are accepted as capable enough to detract organisational members from boredom and stress engendered by the rigid nature of work and its intensity.

Moreover, aesthetics has been deployed in contemporary work organisations to create an impressive image within the minds of its clients, customers as well as workers and to express its unique identity to outsiders (Witz et al., 2003). The distinctive image created by the aestheticized work environment leads to promote the identification of organisational members in relation to the outside world (Gagliardi, 1999). As previous studies done on organisational aesthetics highlight, the aestheticized environment which is constructed by the management of the organisation acts as a means which influences the feelings and desires of organisational members and keeps them attached to the organisation. For example, as Schultz (1992) argues based on postmodern criticisms on organisational 
culture, different aesthetic forms of organisational culture, such as rituals, symbols and artefacts become a "seductive force" to guide the behaviour of organisational members and to keep them embraced to the organisation.

In the process of creating an aestheticized work environment, managers are assumed to play a critical role. Managers are the people who are responsible to get work done from the workers within an organisation and to achieve the goals and objectives of the organisation. To motivate people and to boost their commitment, managers are responsible to create an environment which is conducive to work. Incorporating aesthetics in designing the physical layout of the organisation, introducing activities, such as musical shows and talent shows which generate aesthetic pleasure could be identified as new managerial attempts to keep their subordinates continuously motivated to work (Warren, 2002). This is an attempt made to hide the reality of the working life from the workers. The seductive embrace associated with the aestheticized work environment supports managers to perform their managerial role in a smooth manner. Therefore, there is a high tendency in the current context of aesthetically embellishing the work environment which is rather evident in Sri Lankan work organisations as well.

Thus, despite the lack of Sri Lankan specific literature on aestheticization, as per the ongoing developments in Sri Lanka's corporate sector it can be argued that, the aestheticized environment affects the lives of all organisational members in their daily experience in work milieu in Sri Lanka. It does not only affect the lives of workers but the lives of managers as well. Thus, in the attempt managers make to "seduce" their subordinates, which probably makes the managers "being seduced" by themselves in the 